\title{
O PRINCÍPIO FEDERATIVO: UM PROJETO POLÍTICO-ESPACIAL ALTERNATIVO À LÓGICA DO ESTADO MODERNO ${ }^{1}$
}

\author{
THE FEDERATIVE PRINCIPLE: A POLITICAL-SPATIAL PROJECT \\ ALTERNATIVE TO THE LOGIC OF THE MODERN STATE
}
EL PRINCIPIO FEDERATIVO: UN PROYECTO POLÍTICO-ESPACIAL ALTERNATIVO A LA LÓGICA DEL ESTADO MODERNO

\author{
Rafael Zilio Fernandes - Universidade Federal do Oeste do Pará - Santarém - Pará - Brasil \\ rafael.zilio@yahoo.com.br
}

\begin{abstract}
Resumo
0 Princípio Federativo se inscreve na tradição do pensamento libertário ao longo dos últimos dois séculos como projeto político-espacial alternativo à lógica centralista do Estado moderno. Tal projeto foi objeto de reflexão por parte de diversos autores, inclusive geógrafos. 0 que este artigo traz é um resgate desta tradição sob um olhar geográfico, colocando à luz a espacialidade do Federalismo e identificando o que os autores selecionados entenderam por nação, região e fronteira, ideias importantes para se pensar a organização do espaço humano de modo geral. Primeiramente, mencionam-se antecedentes da sistematização deste Princípio; após, apresenta-se o Federalismo de Proudhon e Bakunin; em seguida, os geógrafos Reclus e Kropotkin são analisados; para o século XX, são abordados Landauer, Rocker e Bookchin. Finalizo colocando algumas ideias para se pensar o Federalismo hoje.
\end{abstract}

Palavras-chave: Federalismo, pensamento libertário, Estado moderno.

\section{Abstract}

The Federative Principle is inscribed in the tradition of libertarian thought over the last two centuries as an alternative political-spatial project to the centralist logic of the modern State. Such project was object of reflection by several authors, geographers included. This paper features this tradition under a geographical approach, highlighting the Federalism's spatiality and identifying what the selected authors understood by nation, region and borders, important ideas to think the organization of human space. First I do a background for the systematization of this Principle; after I present the Federalism for Proudhon and Bakunin; then the geographers Reclus and Kropotkin are analyzed; for the twentieth century I approach ideas from Landauer, Rocker and Bookchin. I end the paper offering some ideas to think the Federalism nowadays.

Keywords: Federalism, libertarian thought, Modern State.

\section{Resumen}

A lo largo de los últimos dos siglos el Principio Federativo se inscribe en la tradición del pensamiento libertario como proyecto político-espacial alternativo a la lógica centralista del Estado moderno. Tal proyecto fue objeto de reflexión por parte de diversos autores, incluso geógrafos. Lo que este artículo trae es un rescate de esa tradición desde el punto de vista geográfico, destacando la espacialidad del Federalismo e identificando lo que los autores seleccionados entendieron por nación, región y frontera, ideas importantes para pensar la organización del espacio humano de modo general. Inicialmente se mencionan los antecedentes de la sistematización de ese Principio; después se presenta el Federalismo de Proudhon y Bakunin; luego, son analizados los geógrafos Reclus y Kropotkin; para el siglo XX son estudiados Landauer, Rocker y Bookchin. Y, por último, finalizo el artículo incluyendo algunas ideas para pensar el Federalismo actual.

Palabras clave: Federalismo, pensamiento libertário, Estado moderno. 
Introdução

Pensar o Princípio Federativo, ou Federalismo, é realizar ao mesmo tempo um exercício de imaginação geográfica e um resgate da experiência humana de resistência ao modelo de organização espacial centralista do Estado territorial moderno. O Federalismo se insere na tradição do pensamento e da práxis libertários ${ }^{2}$ e constitui-se em importante projeto político-espacial que tensiona permanentemente com as instituições heterônomas contemporâneas, majoritariamente o aparelho de Estado.

O que este artigo traz são elementos de contribuição para o campo da Geografia Política, realizando um resgate dessa tradição sob um olhar geográfico, colocando à luz a espacialidade do Federalismo e identificando o que os autores selecionados entenderam por nação, região e fronteira, ideias importantes para se pensar a organização do espaço humano de modo geral e a livre federação de unidades territoriais em particular. Primeiramente, é oferecido um panorama e mencionam-se antecedentes da sistematização desse princípio. Após, apresenta-se o Federalismo de Proudhon e Bakunin. Em seguida, os geógrafos Reclus e Kropotkin são analisados. Para o século XX, são abordados os autores Landauer, Rocker e Bookchin. Por fim, expõem-se algumas ideias para se pensar o Federalismo hoje.

\section{Panorama e antecedentes do Federalismo}

Sinteticamente, o Federalismo pode ser entendido como a projeção espacial do pensamento e da práxis libertários. De um ponto de vista desde a Geografia, é lícito falar, inclusive, que o Federalismo encarna uma geopolítica alternativa à lógica do Estado moderno. Diversos pensadores, acadêmicos ou não, contribuíram para as reflexões e o desenvolvimento desse projeto político-espacial, sempre tendo como pilares as lutas sociais e as práticas espaciais insurgentes de homens e mulheres concretos. A organização política do espaço alternativa ao Estado em geral (não somente o capitalista), na esteira da constituição de uma sociedade com maior justiça social e qualidade de vida, propiciadoras de um desenvolvimento sócio-espacial ${ }^{1}$, e em busca de uma sociedade basicamente autônoma, foram e são objetivos daquelas e daqueles que se empenharam na concretização, ainda que parcialmente, do Federalismo Libertário. 
Uma leitura apressada da geografia (política) histórica das lutas sociais embebida de um olhar conservador e/ou enviesado poderia alegar a impossibilidade de aplicação dos princípios que serão neste artigo apresentados e analisados; porém, diga-se já que os seminais escritos federalistas de anarquistas clássicos como Bakunin e Kropotkin são em parte inspirados na realidade das cidades europeias na chamada baixa Idade Média, e, em experiências de escalas espaciais e temporais diversas, tais princípios tornaram-se práticas espaciais ${ }^{4}$. Logo, compreende-se que o Federalismo Libertário tem uma tradição de pensamento e ação que remete aproximadamente aos últimos 200 anos.

Com o auxílio de um olhar geográfico, é possível depreender que alguns autores se remetem ao que, em nosso campo de conhecimento, é entendido como região. Na maior parte dos escritos, com importantes exceções, as regiões seriam aglomerados de unidades territoriais que corresponderiam a uma escala menor do que a nação ou o país, muito próximo da convencional acepção de região como uma escala intermediária entre o local e o nacional. Já nacionalismo (e nação) foi abordado mais profundamente e de maneira controversa entre os libertários. Encontram-se abordagens biologizantes (a nação é natural ao ser humano, ou seja, toda sociedade humana se estabelece através de nações), posturas naturalizantes ou acríticas (a nação é algo dado, resta refletir sobre o que fazer com ela), posicionamentos de crítica extrema (nação e nacionalismo são intrinsecamente conservadores e reacionários, logo é preciso combater tais ideias) e visões um pouco mais elaboradas (a nação é diferente do aparelho de Estado e legítima componente das sociedades, já o nacionalismo remete à defesa do aparelho de Estado e, portanto, algo a ser combatido).

Diante disso, Grauer (1994) distingue três posturas dos anarquistas clássicos quanto à nação e ao nacionalismo: absoluta rejeição (casos de Proudhon e Bakunin); importância gradual em face de determinadas conjunturas, uma vez que a manutenção de uma "nação-Estado" seria interessante para garantir a não subjugação de um povo por outro, comum em guerras (caso de Kropotkin), e reconhecimento da legitimidade da nação (não confundindo-a com o Estado) como espaço de referência identitária e base de organização social de um grupo humano ou povo (caso dos anarquistas judeus que pensaram os kibutzim na Palestina antes 
do estabelecimento do Estado de Israel), o que curiosamente levou a autora a chamá-los de "anarco-nacionalistas".

$\mathrm{O}$ advento do Estado territorial moderno se deu de forma desigual e com enormes resistências em seu "berço", o continente europeu. Ao final da Idade Média e durante o período renascentista, a Europa apresentava ao menos dois padrões espaciais (Bookchin, 1995): aquele mais conhecido, os feudos, e outro conhecido, porém não tão destacado, o das cidades livremente associadas ${ }^{5}$. Este segundo padrão espacial comportava um grande número de cidades comerciais que, ao se federarem, apresentavam um mercado não capitalista. Nesse contexto, populações tiveram que se identificar com uma "nacionalidade", na qual a noção de cidadania, longamente enraizada na cidade e em seu corpo público, foi dissipada em direção a uma grande entidade territorial - a "nação". Houve, então, profissionalização do poder com o Estado e suas instituições (Bookchin, 1995, p. 159).

Rocker (1933) vai um pouco mais longe na história e afirma que, com a queda de Roma, diversos povos considerados "bárbaros" começaram a se insurgir contra reis e diversas outras autoridades. Com isso, entre os séculos $\mathrm{V}$ e XV, muitas cidades tiveram sua própria constituição, em que suas insuficiências eram supridas através de acordos com outras cidades (comunas medievais). O poder dos soberanos, reis, clérigos etc. era relativamente limitado ao mundo medieval não urbano.

\section{Federalismo para os primeiros anarquistas}

O primeiro militante/pensador a se declarar (e também considerado o primeiro autor) anarquista, Pierre-Joseph Proudhon (1809-1865), deixou diversas reflexões e assentou as bases para o futuro desenvolvimento do Federalismo Libertário. Ele desenvolve suas ideias na contracorrente da época, momento em que a Itália tentava se unificar de forma centralista e os Estados Unidos de uma forma federalista criticada por ele. O único modelo interessante seria o suíço, que ainda assim deveria ser complementado. Sua obra $D u$ principe fédératif, de $1863^{6}$, fornece uma síntese de seu pensamento a respeito da supressão do Estado com a livre federação de unidades territoriais, diferenciando desde então o federalismo propriamente libertário do federalismo administrativo estatal ensinado nos manuais de direito constitucional ${ }^{7}$. 
O pensamento de Proudhon, a partir das considerações feitas por Aníbal D’Auria no prefácio à edição argentina da referida obra, pode ser considerado dialético, porém não uma dialética ao estilo hegelianoidealista nem ao estilo marxiano-materialista: uma dialética dualista e simplificadora, na qual a síntese é o equilíbrio entre os polos e não um produto da contradição entre pares. O principal par dialético movido por Proudhon é o Autoridade-Liberdade: o primeiro corresponde à esfera propriamente familiar que, quando extrapolada para o plano social mais amplo, constitui-se um tipo de autoritarismo a ser combatido; já o segundo seria a esfera do social, na qual o Estado encarnaria a ameaça à Liberdade. O problema do sistema político hegemônico filosoficamente falando, para Proudhon, é que o polo da Autoridade provocou um desarranjo das coisas públicas ao minar a liberdade de associação dos grupos sociais, e o Princípio Federativo serviria para equilibrar os polos.

Para Proudhon, a anarquia remete mais ao plano das ideias e tem relação com o princípio de "cada um por si”, em verdade somente proclamado pelos chamados individualistas da verve de Max Stirner. Já a federação (ou confederação progressiva) combinaria anarquia e democracia (complementares para Proudhon) e também agricultura e indústria (o que Kropotkin anos mais tarde irá aprofundar). A esfera da produção é privilegiada na análise proudhoniana, e as unidades territoriais assim formariam a dita confederação progressiva: comuna agrícola-industrial federação de comunas - confederação (Estado) - federação de Estados.

Nesse caminho, Proudhon (2008, p. 71-72) oferece uma espécie de "passo a passo" para o processo federativo:

$1^{\circ}$ ) formar grupos pequenos, cada um soberano, e uni-los por um pacto de federação;

$2^{\circ}$ ) em cada Estado federado, organizar o governo segundo a lei de separação de órgãos; separar no poder tudo o que seja separável, definir tudo o que seja definível e distribuir entre órgãos ou funcionários distintos tudo o que foi separado e definido; rodear a administração pública de todas as condições de publicidade e controle (transparência);

$3^{\circ}$ ) em vez de absorver sob uma autoridade central os Estados federados ou autoridades provinciais, reduzir as atribuições daquela ao simples rol de iniciativa geral, de garantia mútua e de vigilância: que seus decretos só possam executar-se com vênia dos governos confederados 
e por seus próprios agentes, como faz a monarquia constitucional com toda ordem do rei que requer referendo de um ministro para executar-se.

No contexto da federação progressiva, nações e regiões remetem a escalas apriorísticas. Proudhon vê nação e Estado como complementares, a nação sendo algo dado e natural da organização social humana e o Estado uma expressão dessa organização, podendo este ser o aparelho de Estado como é conhecido ou um Estado-confederação de federações comunais -curiosamente ele não abandona o termo Estado, encaixando-o em seu projeto. O nacionalismo, por outro lado, funcionaria como um motor propulsor do expansionismo dos Estados, devendo ser combatido.

Quanto a regiões, o pensador francês não menciona explicitamente esse termo, porém, da leitura de sua obra, depreende-se que uma região seria um agrupamento de federações em uma escala intermediária entre o local e o "nacional", ou seja, não muito diferente do que é concebido até hoje, ao menos em compreensões leigas. Por sua vez, as fronteiras em seu projeto, implicitamente, seriam as divisões entre as nações, marcando o território de soberania e de "autonomia interna" de um Estadoconfederação. Além disso, deixa claro que fronteiras naturais não existem, pois seriam invenções políticas dos Estados.

O mais conhecido militante do anarquismo clássico, o russo Mikhail Bakunin (1814-1876), nos legou escritos programáticos, panfletos e $\operatorname{cartas}^{8}$ nos quais elabora um programa em direção a uma federação europeia e, após, universal, inspirando-se e avançando em determinados aspectos em relação ao pensamento de Proudhon. O militante russo, bastante simpático ao tipo de federalismo praticado então na Suíça e no norte dos Estados Unidos, almejava a construção do que ele chamou de Estados Unidos da Europa. Para isso, propõe 13 princípios para o Federalismo (Bakunin, 2015 [1867-1868]), similarmente encontrados em seu "Catecismo revolucionário", de 1886.

Sinteticamente, os primeiros princípios defendem que os Estados Unidos da Europa não se formariam a partir dos Estados preexistentes, nem com uma confederação de monarquias, tampouco com uma confederação de Estados centralizados, ainda que se chamem "República”. O quinto princípio nos mostra o que poderíamos denominar uma "política de escalas" no pensamento bakuniniano, revelando, pois, sua sensibilidade espacial: 
Esforçar-se para reconstituir suas respectivas pátrias, a fim de nelas substituir a antiga organização fundada, de cima para baixo, sobre a violência e sobre o princípio da autoridade, por uma organização nova, tendo por base somente os interesses, as necessidades e as atrações naturais das populações, e por princípio somente a federação livre dos indivíduos nas comunas, das comunas nas províncias, das províncias nas nações e, enfim, destas nos Estados Unidos da Europa inicialmente, e mais tarde no mundo inteiro (Bakunin, 2015, p. 22).

O sexto princípio remete à concepção de fronteiras apenas associadas a fronteiras estatais, com absoluta rejeição destas, sejam "naturais" ou não. Em "Catecismo revolucionário", Bakunin reforça a necessidade de se abolir as fronteiras (estatais) em direção à construção de uma federação internacional de países: "Abolição das fronteiras, dos passaportes e das alfândegas. Cada cidadão de um país federado deve desfrutar de todos os direitos políticos em todos os outros países pertencentes à mesma federação" (Bakunin, 2015, p. 163).

O sétimo princípio do Federalismo bakuniniano mostra que a nação, para o autor, é um legítimo e natural aglomerado de pessoas em torno de uma história e de uma cultura (e de um espaço) comuns, e o respeito às nações relaciona-se com a manutenção da autonomia interna e, portanto, da autodeterminação de um povo. Além do reconhecimento da nação como entidade social legítima, uma interessante distinção faz Bakunin entre país e Estado no oitavo princípio - o fato de um país ter feito parte de um Estado não implica obrigação de permanecer nesse Estado; depreendendo-se que, para ele, nação e país seriam sinônimos, porém, numa concepção diferenciada da lógica estatal: "a nação não deve ser nada além de uma federação de províncias autônomas” (Bakunin, 2015, p. 161).

Sintomático do século XIX sob a égide do positivismo e do naturalismo, a naturalização da nação por parte de Bakunin (e também por parte da maioria dos anarquistas da época) é um elemento que, sob a luz do século XXI, deve ser criticado em uma tentativa de atualização do papel das nações no processo de federação de unidades territoriais.

\section{Federalismo para geógrafos "clássicos"}

O geógrafo anarquista Élisée Reclus (1830-1905), na esteira do pensamento naturalista e evolucionista típicos do século XIX (apesar de 
apresentar raciocínio dialético não raras vezes), nos legou reflexões mais profundas acerca do tema das nações/nacionalidades e das fronteiras, conquanto seu pensamento sobre o Federalismo esteja longe de ser ausente de sua obra. Para Reclus, a federação de comunas só seria atingida através de uma melhora ou harmonização das relações sociedade-natureza, com o ser humano adaptando-se às mais variadas condições colocadas pelo espaço “natural”. Podemos dizer que Reclus era um pensador da fraternidade universal entre os seres humanos, entre as gentes de diferentes matrizes culturais ${ }^{9}$, para quem o que chamaríamos hoje de hibridação cultural seria um elemento importantíssimo no processo federativo.

Examinando sua obra-prima, L'homme et la terre ${ }^{10}$ (1905-1908), constata-se a profundidade e a sofisticação, para a época, com que Reclus tratava de temas como nações e fronteiras. A pátria, para ele, remetia à extrapolação da significação imaginária da propriedade privada, onde se constitui um território ao redor do qual todos os outros são potenciais inimigos. As pátrias e os nacionalismos assim se colocam como inimigos da fraternidade universal ao mobilizarem elementos do universo de valores e símbolos de um povo (língua, sentimentos de pertencimento a lugares e regiões, etc.), onde as fronteiras estatais (muitas vezes travestidas de "naturais") cumprem o papel de separação e de zona de controle (a crítica às fronteiras naturalizadas pode ser encontrada em diversas passagens da obra de Reclus). O interessante é notar que o geógrafo francês já tinha em mente a grande artificialidade e as inúmeras limitações de se tomar o mapa do mundo dividido em Estados e fronteiras estatais, um raciocínio muito caro para um olhar libertário. Assim, chega-se ao problema da divisão do espaço em Estados e suas fronteiras estatais:

El planeta esta recortado políticamente por una red de fronteras que dividen las diversas partes de la Tierra declaradas propiedad imperial, real ó nacional, y se ha de realizar toda una revolución de pensamiento antes de modificar á este aspecto las convenciones tradicionales (Reclus, 1906-1909, p. 326).

Ao invocar a necessidade de uma revolução de pensamento para se modificar as convenções tradicionais de separação do globo em Estados ou Impérios (ou mais apropriadamente: em estruturas territoriais heterônomas), identificamos o embrião de uma linha de raciocínio que chegaria à segunda metade do século XX com o libertário Castoriadis e com outros autores muito próximos do pensamento 
libertário, como Deleuze e Guattari ${ }^{11}$, ainda que não façam menção a Reclus: o Estado como estrutura territorial heterônoma de governo de homens e mulheres e historicamente datado utiliza-se de significações imaginárias que permitem a internalização/"aceitação" e "naturalização" de sua existência (impacto na subjetividade) sem a necessidade, muitas vezes, de justificativas mais claras ou racionais (o Estado é consequência natural da evolução da sociedade, todos os homens e mulheres devem ter nacionalidade sob pena de não se encaixarem na sociedade - caso não só de apátridas mas também de todas e todos aquelas[es] excluídos do ou precariamente incluídos no modelo civilizatório hegemônico, ou que não têm sua "cidadania" efetivada). Por isso, a instituição do Estado também se dá no âmbito da psique ${ }^{12}$. Logo, a superação da lógica estatal não reside apenas em uma simples destruição do Estado (como diria Bakunin), mas também na modificação das significações imaginárias sociais na esteira de inúmeras revoluções moleculares ${ }^{13}$, ou seja, mudanças não somente nas relações sociais e no espaço, mas também na psique. Isso não esquecendo que, para Reclus, a evolução e a revolução caminham juntas, sendo a última um momento de evolução mais rápido.

O geógrafo francês vai ainda mais fundo na análise das bordas dos Estados ao problematizar a securitização das fronteiras, um debate bastante contemporâneo e que, para ele, há mais de cem anos, já era objeto de reflexão. Reclus relaciona muito bem a psique com as relações sociais e com a espacialidade ao falar do "hipnotismo" que as fronteiras causam nos agentes de segurança nacional (Reclus, 1906-1909, v. 5, p. 332).

Além do controle da mobilidade populacional em um espaço altamente securitizado, as fronteiras (estatais) acabam se justificando pela invocação do nacionalismo, delimitando, inclusive, o "fim" de um modo de organização social e o "início" de outro. Reclus atenta para a mobilidade de pessoas em regiões fronteiriças, e que as divisões estatais não seriam capazes de tolher as trocas entre comunidades a não ser pela privação de liberdade com os dispositivos de segurança fronteiriços (Reclus, 19061909, p. 341).

Nesse contexto, Reclus vislumbra uma tendência à extrapolação das fronteiras (que mudam com frequência, pois historicamente datadas) e uma migração cada vez mais acentuada, uma vez que as ligações dos indivíduos com seu torrão natal se fariam mais frágeis. Não seria, este, 
um raciocínio precursor de ideias que contemporaneamente associamos ao fenômeno da globalização e de seus reflexos culturais e identitários?

Considerando que fronteiras "naturais" seriam invenções conjunturais fruto da constituição dos Estados, o intercâmbio cultural livre passaria necessariamente por federações de comunas livres. Nesse sentido, pode-se afirmar que, a partir do pensamento de Reclus, as fronteiras "legítimas" de um ponto de vista anti-heterônomo seriam aquelas advindas da transição entre uma região (como espaço vivido) e outra, aproximando-se da noção de "fronteiras culturais".

Outro geógrafo anarquista muito importante no desenvolvimento do Federalismo Libertário é o russo Piotr Kropotkin (1842-1921), que foi responsável por espacializar e refinar o acúmulo de ideias a respeito do Princípio Federativo até então. A obra em que podemos encontrar seus mais profundos insights sobre a organização espacial federalista é Fields, factories and workshops, cuja primeira edição data de $1898^{14}$. Nela, Kropotkin vislumbra duas dimensões básicas do projeto federalista: a desconcentração econômico-espacial e a descentralização territorial. Com uma combinação entre agricultura e indústria, por um lado, e com a superação da separação entre trabalho manual e trabalho intelectual, por outro, ter-se-ia o caminho para a primeira dimensão. Já o estabelecimento de comunas livres e redes multiescalares de federação entre as comunas corresponderia à segunda dimensão.

No Federalismo de Kropotkin, a dimensão econômica tem um peso significativo. Adepto do chamado anarco-comunismo (sintetizado na máxima "de cada um segundo suas possibilidades, a cada um segundo suas necessidades”), o geógrafo russo concebia como inseparável o econômico das esferas de decisão política em assembleias locais e em federações para dar cabo de assuntos em escalas supralocais. O pensamento espacial kropotkiniano abarca uma multiescalaridade que, porém, confere a primazia para a escala local - a escala da produção e do consumo propriamente ditos.

O verbete "Anarquismo", da Enciclopédia britânica publicada em 1910, escrito por Kropotkin, sumariza seu projeto federalista, resumindo as reflexões libertárias até então acumuladas e também avançando em determinados aspectos. Eis alguns trechos:

Períodos de rápidas mudanças seguir-se-ão a períodos de lenta evolução, e é preciso tirar vantagem desses períodos - não para 
aumentar e ampliar os poderes do Estado, mas sim para reduzi-los, através da organização, em cada distrito ou comuna, dos grupos locais de produtores e consumidores, bem como das federações regionais e eventualmente internacionais desses grupos.

$[\ldots]$

Repudiando toda legislação, mesmo quando originada do sufrágio universal, Bakunin exigiu, para cada nação, cada região e cada comuna, plena autonomia, desde que isso não se constitua em uma ameaça para os seus vizinhos, e plena independência para o indivíduo, acrescentando que só é possível tornar-se realmente livre quando e na medida em que todos os outros forem livres, Federações livres de comunas constituiriam nações livres (Kropotkin, 1910 apud Souza, 2017, p. 176).

A nação, para Kropotkin, conforme adiantado na menção à Grauer (1994, p. 3), é um agrupamento legítimo de pessoas em torno de sentimentos, valores e espaços comuns. A autora destaca que Kropotkin e seus seguidores apresentaram uma abordagem gradualista quanto à nação: nacionalismo e internacionalismo serviriam a dois propósitos diferentes em tempos diferentes no desenvolvimento histórico da ordem social ideal. O nacionalismo é visto como força necessária para livrar as pessoas da dominação externa/estrangeira. Depois que a independência nacional fosse atingida, as pessoas poderiam canalizar seus recursos e motivações e lutar por uma nova ordem mundial de acordo com princípios internacionalistas. O geógrafo russo considerou interessante o papel dos movimentos de libertação nacional em geral, sendo isto uma força positiva no processo de destruição da sociedade capitalista (Grauer, 1994, p. 6) - o que remete à aproximação dele com os anarquistas judeus próximos ao movimento sionista. Logo, Kropotkin não via o nacionalismo (ou, melhor, um tipo de nacionalismo) e o internacionalismo como teses conflitantes, mas sim complementares. A verdadeira harmonia entre nações seria atingida se cada nação tivesse a oportunidade de se desenvolver livremente, sem opressões estrangeiras. O completo desenvolvimento de cada nação asseguraria a existência harmônica da humanidade (Grauer, 1994, p. 17).

Kropotkin entendia a região como uma escala intermediária entre o local e o nacional, uma primeira e mais imediata escala de associação de unidades territoriais (comunas). As fronteiras, no entanto, não são explicitamente mencionadas nem debatidas de maneira mais profunda, 
somente sendo invocadas para se fazer menção às bordas dos Estados ou à divisão entre nações.

\section{Federalismo para anarquistas do século XX}

Inspirado em muito no pensamento de Kropotkin, o anarquista alemão Gustav Landauer (1870-1919) legou-nos refinamento das reflexões sobre nação, Estado e comunidade, entre outros elementos. Uma primeira e importante contribuição é a ideia, mais além da de Kropotkin, de que o Estado, em sua natureza, não é uma instituição que possa ser destruída por uma revolução. O Estado é uma relação social, um condicionante do comportamento social; nós o eliminamos construindo outras sociabilidades, valorizando a vida comunitária (que sempre esteve presente na história da humanidade) até que as relações comunitárias fortaleçam-se a ponto de suprimir o Estado, conforme encontra-se em diversos escritos de Landauer (2010) ${ }^{15}$ e é também destacado por Buber (1949, p. 46 e 49).

Landauer distingue epistemologicamente a nação do Estado o Estado é uma estrutura política artificial nascida de determinados processos históricos mais do que fruto da experiência natural das pessoas; já a nação seria próxima da noção de volk (povo), uma entidade de desenvolvimento "orgânico" que sempre existe, independente de aparelho de Estado. Ambos são constructos sociais, porém a nação se distingue ao encorajar a autodeterminação dos povos (volks) e o ativismo social, enquanto o Estado traz autoritarismo, escravidão e passividade (cf. Grauer, 1994, p. 7).

Para além das ideias de nação, Estado e comunidade, Landauer desenvolve uma terceira "entidade”, o Espírito (Geist), que não está presente no Estado, enquanto o volk tem um "Espírito" que liga cada indivíduo à comunidade, uma espécie de legitimidade comunitária. O volk, pois, é uma unidade cultural e espiritual, não uma estrutura política ou econômica, nem uma entidade biológica determinada por laços de sangue fixos e inalteráveis (Grauer, 1994, p. 8). Esclarecendo o "Espírito” em Landauer, Buber (1949, p. 51) explica que o Geist não é mero produto ou reflexo do mundo material, mera "consciência" determinada pelo ser social e explicado em termos de relações técnico-econômicas. É mais um dado sui generis do indivíduo em relação ao ser social, o que apresenta algumas conexões com o imaginário em Castoriadis ${ }^{16}$, construindo-se uma ponte 
entre libertários de diferentes épocas. Contrastando com Bakunin, que via a rejeição da nacionalidade como pré-requisito para o universalismo, Landauer via a nacionalidade como parte essencial da existência.

Um último elemento de destaque é o que Landauer chamou de comunidade regional (Buber, 1949, p. 49). Primeiramente, para ele, a comunidade sempre esteve presente na história humana - já mencionado aqui. O que o socialismo libertário faz é destacá-la e colocá-la à frente de qualquer Estado. No momento em que as relações comunitárias fortes suprimem o Estado e a nacionalidade permanece mesmo quanto o Estado é eliminado, a comunidade regional torna-se uma entidade geográfica fundamental para o estabelecimento do Federalismo. A escala regional é valorizada por ser o que poderíamos chamar de um espaço vivido e experenciado, um espaço de construção de sociabilidades, sendo que cada comunidade regional deve estabelecer suas próprias fronteiras em negociação livre com outras comunidades regionais. Assim, da comunidade singular à nação, temos uma federação de comunidades em escala regional (entre o local e o nacional).

Um dos escritores que mais profundamente se debruçou sobre o tema do nacionalismo no âmbito do anarquismo clássico foi o alemão Rudolf Rocker (1873-1958). Historiador, propagandista e anarcossindicalista, defendia que a nação não é naturalizável nem tampouco um agrupamento necessariamente legítimo como uma família ou uma tribo - o indivíduo não nasce "nacional", ele precisa ter a nação internalizada no processo de socialização em determinado contexto cultural. Em sua obra Nationalism and culture, Rocker (1933) traça o desenvolvimento da ideia de nação do princípio da história humana aos tempos modernos, concluindo que os sentimentos nacionais não são nem inerentes nem naturais. Um indivíduo não é ligado naturalmente à nação como o é à família ou à tribo, ele precisa ser treinado para pensar que é parte de uma nação de maneira similar a como se fosse parte de uma Igreja.

A consciência nacional é mais um constructo artificial que não emerge das pessoas, e sim precisa ser imposto. Grauer (1994, p. 8), comentando Rocker, destaca a distinção entre folk e Estado utilizada por ele na análise do nacionalismo e do desenvolvimento histórico, na qual o folk é o resultado da união social externo (independente) ao Estado. Contrapondo o Estado ("poder”) e a cultura, para ele nada é mais errôneo do que associar o Estado ao progresso cultural da humanidade. O Estado 
foi desde o início a força impeditiva do desenvolvimento de qualquer forma cultural de maior expressão; sendo assim, Estados não criam cultura, e poder (Estado) e cultura são no final opostos e irreconciliáveis ${ }^{17}$. Um aparelho estatal poderoso é o maior obstáculo para qualquer desenvolvimento cultural: onde os Estados estão morrendo, ou onde seu poder é bastante limitado, a cultura floresce melhor (Rocker, 1933, p. 46).

O Federalismo é uma necessidade de organização social em seu pensamento através do consenso, das uniões voluntárias e da unidade de objetivos, uma unidade de forças de comunidades livres. Para um movimento autenticamente libertário, o federalismo é a única forma de organização possível; longe de significar o esmigalhamento das forças e de opor-se a uma ação unificada, ele é, ao contrário, unidade das forças, mas que se apoia sobre a ação voluntária e livre de cada grupo particular, sobre a solidariedade viva de sua comunidade (Rocker, 2007, p. 133-134).

Regiões e fronteiras não são termos correntes em seus escritos, uma vez que o espaço é poucas vezes mencionado diretamente. Assim como em Bakunin, a região está nas entrelinhas, aproximando-se do princípio ontológico da diferenciação do espaço; já as fronteiras são simplesmente as bordas dos Estados e, portanto, devem ser destruídas.

Décadas após a queda dos anarquistas na Guerra Civil Espanhola, momento tido como o fim do anarquismo clássico, o estadunidense Murray Bookchin (1921-2006) renova e refina o pensamento libertário com uma sensibilidade espacial profunda, conferindo ao Princípio Federativo novos contornos com suas propostas de municipalismo libertário ${ }^{18}$ e de confederalismo. O municipalismo libertário traz a valorização político-pedagógica da escala local como escala humana de estabelecimentos de assembleias em situação de copresença mesmo nos grandes centros urbanos globais.

A combinação entre luta institucional e ação direta, a despeito de ter gerado acalorados debates nos meios libertários, aparece como uma renovação das ideias federalistas ao não reduzir noções como poder (algo não necessariamente ruim), governo (qualquer associação ou institucionalidade relacionada aos negócios públicos) e lei (necessária em qualquer organização social, assim como pensava Castoriadis), entendendo o Estado como uma instância complexificada em que certas brechas de determinadas conjunturas podem ser aproveitadas para fins de ganhos de autonomia, tomando a ação direta como necessidade e a luta institucional 
como possibilidade ${ }^{19}$. Com isso, a práxis libertária deve lidar com as próprias contradições do Estado, aproveitando instâncias para retomar a riqueza socialmente produzida e municipalizar a economia, devolvendo à cidade o seu caráter efetivamente público de debates e de tomada de decisões coletivas.

Ao contrário das propostas de alguns anarquistas clássicos, o Federalismo de Bookchin é primordialmente espacial, e não setorial, sendo que a sensibilidade espacial de Boockhin não se esgota na escala local. Ele entende o processo federativo em sua multiescalaridade, colocando uma agenda supralocal para além da agenda municipal (Bookchin, 1995, p. 244): a substituição do Estado por uma rede confederada de assembleias municipais na qual todas as formas de propriedade social fossem absorvidas por uma economia política em que municipalidades, interagindo entre si economicamente e politicamente, solucionariam seus problemas materiais como cidadão em assembleias abertas (e não apenas como profissionais setoriais), as municipalidades aí colocadas em escala humana e descentralizadas fisicamente.

Para além, Bookchin (2002) vislumbra uma unidade territorial em escala regional fundamental para o seu municipalismo: a township. Sob inspiração de uma divisão administrativa presente em algumas partes dos Estados Unidos, a township seria uma região dentro de outras regiões maiores que transcenderia a oposição campo-cidade, com um espaço urbano como núcleo de sua produção rural e dos vilarejos dos arredores, de modo semelhante ao imaginado por Kropotkin. A visão escalar de Bookchin se expressa também ao tratar sua proposta confederalista de modo a evitar territorialismos ou paroquialismos através da interdependência de regiões com controle público.

Bookchin menciona poucas vezes o termo nação, majoritariamente associando-o ao Estado (Estado-nação) e a uma escala (nacional); o nacionalismo é simplesmente um movimento reacionário (Bookchin, 2002). Por sua vez, não foram encontradas menções a fronteiras nas obras consultadas, apenas rápidas referências às bordas dos Estados.

Sintetizando em direção ao Federalismo hoje

Para pensarmos a organização espacial na contemporaneidade a partir do Princípio Federativo, é importante conhecer a trajetória 
intelectual e o legado deixado pelos autores e pelas experiências concretas ao longo da história. Neste artigo, por motivos de foco, optou-se por abordar escritos de pensadores-militantes, considerando a interessante disponibilidade de análises da práxis, como os supracitados Samis (2011) e Rodrigues (2016), bem como Brancaleone (2015) e Öcalan (2016), que estudaram os casos dos zapatistas ao sul do México e dos curdos ao norte da Síria, respectivamente.

A título de síntese das ideias-chave analisadas no presente artigo (Federalismo, nação, região e fronteira), temos o Quadro 1.

\begin{tabular}{|c|c|c|c|c|}
\hline & FEDERALISMO & NAÇÃO & REGIÃO & FRONTEIRA \\
\hline PROUDHON & $\begin{array}{l}\text { Expressão do equilíbrio } \\
\text { entre Autoridade e } \\
\text { Liberdade; } \\
\text { federação agrícola- } \\
\text { industrial (esfera da } \\
\text { produção). "Estados" } \\
\text { são confederações de } \\
\text { federações comunais. }\end{array}$ & $\begin{array}{c}\text { Nação é algo } \\
\text { dado, natural da } \\
\text { organização das } \\
\text { sociedades humanas. } \\
\text { Nação e povo são } \\
\text { sinônimos. } \\
\text { Nacionalismo é motor } \\
\text { do expansionismo } \\
\text { dos Estados. }\end{array}$ & $\begin{array}{c}\text { Agrupamento de } \\
\text { federações em uma } \\
\text { escala intermediária } \\
\text { entre o local e o } \\
\text { nacional. }\end{array}$ & $\begin{array}{c}\text { Implícitas entre } \\
\text { "Estados" federados } \\
\text { / confederações. } \\
\text { Não existem } \\
\text { fronteiras naturais, } \\
\text { somente fronteiras } \\
\text { políticas. }\end{array}$ \\
\hline BAKUNIN & $\begin{array}{l}\text { Coletivismo; "a cada um } \\
\text { segundo o seu trabalho"; } \\
\text { política de escalas na } \\
\text { construção dos Estados } \\
\text { Unidos da Europa. }\end{array}$ & $\begin{array}{l}\text { Nação não deve } \\
\text { ser nada além de } \\
\text { uma federação } \\
\text { de províncias } \\
\text { autônomas. } \\
\text { Nacionalidade } \\
\text { é natural e um } \\
\text { direito universal } \\
\text { que corresponde à } \\
\text { autodeterminação } \\
\text { dos povos. }\end{array}$ & $\begin{array}{l}\text { Não mencionada } \\
\text { diretamente, lê-se } \\
\text { nas entrelinhas. } \\
\text { Próxima do princípio } \\
\text { ontológico da } \\
\text { diferenciação do } \\
\text { espaço. }\end{array}$ & $\begin{array}{l}\text { Rejeição do "direito } \\
\text { histórico" do Estado } \\
\text { quanto a fronteiras } \\
\text { naturais, políticas, } \\
\text { estratégicas, etc. } \\
\text { Supressão das } \\
\text { fronteiras. }\end{array}$ \\
\hline RECLUS & $\begin{array}{c}\text { Alcançado com a } \\
\text { supressão da ordem } \\
\text { estatal, com a } \\
\text { harmonização da relação } \\
\text { sociedade-natureza e com } \\
\text { o "progresso". } \\
\text { Comunas livres ajustadas } \\
\text { o mais possível ao espaço } \\
\text { "natural" }\end{array}$ & $\begin{array}{c}\text { Nação é um } \\
\text { agrupamento } \\
\text { identitário legítimo. } \\
\text { Nacionalidade } \\
\text { e nacionalismo } \\
\text { justificam as } \\
\text { fronteiras (estatais), } \\
\text { dificultando a } \\
\text { fraternidade entre os } \\
\text { povos, e devem ser } \\
\text { combatidos. }\end{array}$ & $\begin{array}{l}\text { Porção do espaço } \\
\text { diferenciada sob } \\
\text { algum critério, } \\
\text { próximo do princípio } \\
\text { ontológico da } \\
\text { diferenciação do } \\
\text { espaço. }\end{array}$ & $\begin{array}{l}\text { Invenções humanas } \\
\text { conjunturais } \\
\text { e móveis } \\
\text { (historicidade } \\
\text { da fronteira) } \\
\text { justificadas pelas } \\
\text { nacionalidades. }\end{array}$ \\
\hline
\end{tabular}




\begin{tabular}{|c|c|c|c|c|}
\hline KROPOTKIN & $\begin{array}{l}\text { Anarco-comunismo; } \\
\text { combinação entre } \\
\text { agricultura e indústria; } \\
\text { "de cada um segundo } \\
\text { suas possibilidades, } \\
\text { a cada um segundo } \\
\text { suas necessidades". } \\
\text { Desconcentração } \\
\text { econômico-espacial } \\
\text { + descentralização } \\
\text { territorial. }\end{array}$ & $\begin{array}{l}\text { Nações podem ter } \\
\text { caráter legítimo e } \\
\text { identificam um povo } \\
\text { com seu espaço; } \\
\text { nacionalismo } \\
\text { relaciona-se a } \\
\text { Estados e deve ser } \\
\text { combatido. }\end{array}$ & $\begin{array}{l}\text { Agrupamento de } \\
\text { comunas livremente } \\
\text { federadas em uma } \\
\text { escala intermediária } \\
\text { entre o local e o } \\
\text { "nacional". }\end{array}$ & $\begin{array}{l}\text { Implicitamente, } \\
\text { divisões entre } \\
\text { Estados ou entre } \\
\text { nações. }\end{array}$ \\
\hline LANDAUER & $\begin{array}{l}\text { Livre associação entre } \\
\text { comunidades regionais, } \\
\text { nível entre a comunidade } \\
\text { local e a nação. }\end{array}$ & $\begin{array}{c}\text { Nação e } \\
\text { nacionalidade } \\
\text { são elementos } \\
\text { identitários legítimos } \\
\text { em qualquer } \\
\text { sociedade e podem } \\
\text { existir independentes } \\
\text { de Estado. }\end{array}$ & $\begin{array}{c}\text { Comunidade } \\
\text { regional: sentimento } \\
\text { de pertencimento } \\
\text { a uma comunidade } \\
\text { em escala } \\
\text { regional. Região } \\
\text { é espaço vivido, } \\
\text { experenciado e de } \\
\text { socialização. }\end{array}$ & $\begin{array}{c}\text { Zonas entre } \\
\text { comunidades } \\
\text { regionais livremente } \\
\text { negociadas entre as } \\
\text { partes. }\end{array}$ \\
\hline ROCKER & $\begin{array}{l}\text { Unidade de forças de } \\
\text { comunidades livres. }\end{array}$ & $\begin{array}{l}\text { Nações são produtos } \\
\text { de socializações } \\
\text { autoritárias e devem } \\
\text { ser combatidas, não } \\
\text { naturalizadas. }\end{array}$ & $\begin{array}{l}\text { Não mencionada } \\
\text { diretamente, lê-se } \\
\text { nas entrelinhas. } \\
\text { Próxima do princípio } \\
\text { ontológico da } \\
\text { diferenciação do } \\
\text { espaço (como } \\
\text { Bakunin). }\end{array}$ & $\begin{array}{c}\text { Bordas dos Estados } \\
\text { que devem ser } \\
\text { destruídas. }\end{array}$ \\
\hline BOOKCHIN & $\begin{array}{c}\text { Municipalismo libertário; } \\
\text { luta institucional e ação } \\
\text { direta; primazia da escala } \\
\text { local e de situações de } \\
\text { co-presença (assembleias } \\
\text { espacialmente - e } \\
\text { não setorialmente - } \\
\text { referenciadas) }\end{array}$ & $\begin{array}{l}\text { Nação é próximo de } \\
\text { Estado. } \\
\text { Nacional refere-se a } \\
\text { uma escala. } \\
\text { Nacionalismo é } \\
\text { um movimento } \\
\text { reacionário. }\end{array}$ & $\begin{array}{c}\text { Township: } \\
\text { transcende a } \\
\text { oposição campo- } \\
\text { cidade; uma região } \\
\text { em que a entidade } \\
\text { urbana é o núcleo } \\
\text { de sua agricultura } \\
\text { e dos vilarejos } \\
\text { próximos. }\end{array}$ & $\begin{array}{l}\text { Implicitamente, as } \\
\text { bordas dos Estados. }\end{array}$ \\
\hline
\end{tabular}

Quadro 1 - Síntese de ideias selecionadas do anarquismo

Fonte: Elaboração do autor, 2017.

Ao pensarmos o mundo contemporâneo, altamente globalizado para o fluxo de capitais e de (algumas) pessoas, diversos avanços, atualizações e correções devem ser feitos para lidarmos com a realidade e não termos em mãos e mentes um projeto anacrônico. Tomando por base a tradição do Federalismo no pensamento libertário, Souza (2006) defende uma organização espacial compatível com a autonomia que não 
resvale em territorialismos ou paroquialismos que uma democracia de escala local poderia acarretar. A descentralização territorial radical deve ser acompanhada por uma ciberdemocracia e por refuncionalizações e reestruturações espaciais que democratizem as modernas tecnologias de comunicação e informação e combatam a "ditadura dos grandes números"; longe de um retorno bucólico e ingênuo a um passado mitificado rural e "puro", é necessário lidar com um espaço densamente habitado por milhões de pessoas.

Não se trata, pois, de um pensamento teleologista ou etapista, mas sim um exercício de imaginação geográfica com a elaboração de cenários futuros baseados nas lutas concretas do passado e do presente, já que seria um equívoco "querer antecipar teoricamente algo que compete à história decidir: os formatos institucionais concretos de uma hipotética sociedade do futuro, basicamente não-heterônoma” (Souza, 2006, p. 551552). Assim, o Princípio Federativo na tradição do pensamento e da práxis libertários se faz relevante para análises da Geografia Política e se coloca como uma geopolítica alternativa e uma inspiração para refletirmos sobre a organização política do espaço humano de uma maneira emancipatória e tendo a autonomia como horizonte de pensamento e ação.

\section{Notas}

1 Este artigo é baseado em um capítulo de minha tese de doutorado defendida junto ao Programa de Pós-Graduação em Geografia da UFRJ em dezembro de 2017.

20 pensamento e a práxis libertários caracterizam-se por uma multiplicidade de correntes e perspectivas que vão desde o anarquismo clássico, passando pelo neoanarquismo e pelo autonomismo contemporâneos. O que tais perspectivas têm em comum é, ao mesmo tempo e entre outras coisas, a rejeição simultânea do modelo civilizatório capitalista (Estado capitalista incluso) e das alternativas burocrático-centralistas advindas do marxismo-leninismo. Para maior aprofundamento, ver Souza (2017).

3 Consulte-se, sobre o desenvolvimento sócio-espacial, Souza (1996; 2013).

40 Federalismo foi colocado em prática em diversos momentos da história e com resultados mais ou menos exitosos. A respeito de dois desses momentos, a Comuna de Paris e a revolução durante a Guerra Civil Espanhola, consulte-se Samis (2011) e Rodrigues (2016).

5 Exemplos são as cidades mediterrâneas, como Gênova e Veneza, e a chamada Liga Hanseática, cuja espacialidade abrangia o norte da Europa e as proximidades do Mar Báltico. 
6 Para o presente trabalho consultei a edição argentina El principio federativo, publicada em Buenos Aires em 2008.

7 E que inspirou a formação dos Estados Unidos da América, entre outros aparelhos de Estado federativos.

8 Para o presente texto foi consultado majoritariamente o livro Mikhail Bakunin: obras escolhidas, organizado por Plínio Augusto Coelho e publicado pelas editoras Hedra e Imaginário em 2015.

9 Ainda que aqui e acolá Reclus tenha sido um tanto condescendente com uma espécie de "colonialismo humanitário" em algumas colônias de povoamento, resvalando em etnocentrismo. Ver, sobre isso, Badouin (2009) e Souza (2017, p. 123).

10 Para o presente artigo foi consultada a tradução para o espanhol El hombre y la tierra, publicada em Barcelona entre 1906 e 1909.

11 A respeito das repercussões das estruturas heterônomas na subjetividade dos sujeitos, consulte-se, entre outras obras, Guattari (1987) e Deleuze e Guattari (1995).

12 Tendo em mente o tripé psique-relações sociais-espaço: "a sociedade concreta só existe com esse três 'componentes' ao mesmo tempo porque cada um deles é relacional e, assim, só pode ser concebido, no plano concreto, em relação com os demais e incorporando, de certo modo, os demais" (SOUZA, 2017, p. 46, grifo do original).

13 Mais sobre revolução molecular em Guattari (1987).

14 Para o artigo, consultou-se a segunda edição do livro, publicada em 1901.

15 Compilação de escritos que datam das primeiras duas décadas do século XX.

16 A respeito das significações imaginárias sociais, consultar Castoriadis (1983).

17 Ao oferecer a problemática oposição poder $x$ cultura, reduzindo o poder a algo negativo e ao aparelho de Estado (comum no anarquismo clássico), Rocker restringe as potencialidades que uma abordagem libertária da cultura poderia apresentar; as nações de fato são construções sociais e não naturais (nisso o autor avança sobre o pensamento de anarquistas anteriores), mas confundir o poder com o Estado e tomá-lo com apenas destrutivo ofusca uma visão que entende a cultura, ou melhor, a dimensão simbólicocultural da sociedade, como fundamental para o desenvolvimento das lutas sociais em geral, tornando-a dimensão político-cultural.

18 Para Bookchin, o município de sua proposta não corresponde à divisão administrativa estatal mas sim à escala local, à unidade territorial que, na tradição do pensamento libertário, foi chamada de comuna.

19 Mais sobre a questão da luta institucional e da ação direta em uma perspectiva libertária encontra-se em Souza (2015, p. 55 e segs.).

\section{Referências}

BADOUIN, A. Reclus: a colonialist? Cybergeo - European Journal of Geography, artigo 239, 2009. Disponível em: <http://cybergeo.revues.org/4004\#text>. Acesso em: 7 nov. 2017. 
BAKUNIN, M. Obras escolhidas. São Paulo: Hedra; Imaginário, 2015.

BOOKCHIN, M. From urbanization to cities: toward a new politics of citizenship. New York: Cassell, 1995.

. Libertarian municipalism: the new municipal agenda. 2002. Disponível em: <http://dwardmac.pitzer.edu/bookchin/libmuni.html>. Acesso: em 20 maio 2014.

BRANCALEONE, C. Teoria social, democracia e autonomia: uma interpretação da experiência de autogoverno zapatista. Rio de Janeiro: Azougue Editorial, 2015.

BUBER, M. Paths in utopia. Londres: Routledge \& Kegan Paul, 1949.

CASTORIADIS, C. [1975]. A instituição imaginária da sociedade. Rio de Janeiro: Paz e Terra, 1983.

DELEUZE, G.; GUATTARI, F. Introdução: rizoma. In: capitalismo e esquizofrenia. São Paulo: Ed. 34, 1995 [1980]. (v. 1). Mil platôs:

GRAUER, M. Anarcho-nationalism: attitudes towards jewish nationalism and zionism. Modern Judaism, v. 14, n. 1, 1994.

GUATTARI, F. Revolução molecular: pulsações políticas do desejo. São Paulo: Brasiliense, 1987 [1980].

KROPOTKIN, P. A. Fields, factories and workshops. Or industry combined with agriculture and brain work with manual work. 2. ed. Londres: Swan Sonnenschein \& Co., 1901.

. Anarchism. In: The Encyclopaedia Britannica. Londres: [s.n.], 1910.

LANDAUER, G. Revolution and other writings. A political reader. Oakland: PM Press, 2010.

ÖCALAN, A. Confederalismo democrático. Rio de Janeiro: Rizoma Editorial, 2016.

PROUDHON, P-J. [1863]. El principio federativo. Buenos Aires: Libros de Anarres, 2008.

RECLUS, É. [1905-1908]. El hombre y la tierra. 6 tomos. Barcelona: Escuela Moderna, 1906-1909.

ROCKER, R. Nationalism and culture. [S.l.]: The Anarchist Library, 1933. . [1921]. Os sovietes traídos pelos bolcheviques. São Paulo: Hedra, 2007.

RODRIGUES, G. B. A experiência da autogestão territorial anarquista durante a Guerra Civil Espanhola (1936-1939): legado, limites e possibilidades. Boletim Gaúcho de Geografia, Porto Alegre, v. 43, n. 1, 2016.

SAMIS, A. Negras tormentas: o federalismo e o internacionalismo na Comuna de Paris. São Paulo: Hedra, 2011.

SOUZA, M. L. de. A teorização sobre o desenvolvimento em uma época de fadiga teórica, ou: sobre a necessidade de uma "teoria aberta" do desenvolvimento sócio-espacial. Território, Rio de Janeiro, n. 1, 1996. 
. A prisão e a ágora: reflexões em torno da democratização do planejamento e da gestão das cidades. Rio de Janeiro: Bertrand Brasil, 2006.

. Os conceitos fundamentais da pesquisa sócio-espacial. Rio de Janeiro: Bertrand Brasil, 2013.

. Dos espaços de controle aos territórios dissidentes. Escritos de divulgação científica e análise política. Rio de Janeiro: Consequência, 2015.

. Por uma geografia libertária. Rio de Janeiro: Consequência, 2017.

Rafael Zilio Fernandes - Bacharel em Geografia e Licenciado em Geografia pela Universidade Federal do Rio Grande do Sul. Mestre e Doutor em Geografia pela Universidade Federal do Rio de Janeiro. Professor do curso de Geografia da Universidade Federal do Oeste do Pará. ORCID: https://orcid.org/0000-0003-1880-3664

Recebido para publicação em 17 de janeiro de 2018 Aceito para publicação em 9 de março de 2018 